\title{
Cancer stem cell biomarkers for head and neck squamous cell carcinoma: A bioinformatic analysis
}

\author{
MENG XIAO ${ }^{1,2^{*}}$, LIU LIU $^{1,2^{*}}$, SHIJIAN ZHANG ${ }^{1,2}$, \\ XI YANG ${ }^{1,2}$ and YAN'AN WANG ${ }^{1,2}$ \\ ${ }^{1}$ Department of Oral and Maxillofacial-Head and Neck Oncology, Shanghai Ninth People's Hospital, \\ Shanghai Jiao Tong University, School of Medicine, Shanghai 200011; ${ }^{2}$ Shanghai Key Laboratory of Stomatology \\ and Shanghai Research Institute of Stomatology, Shanghai Jiao Tong University, Shanghai 200011, P.R. China
}

Received May 23, 2018; Accepted October 1, 2018

DOI: $10.3892 /$ or.2018.6771

\begin{abstract}
Several putative biomarkers have been reported to identify cancer stem cells (CSCs) in head and neck squamous cell carcinoma (HNSCC). Herein, we aimed to demonstrate the validity and the underlying relationship for these biomarkers in HNSCC. Bioinformatic analyses for the reported CSC biomarkers of HNSCC were performed based on the TCGA primary HNSCC cohort using the UCSC Xena browser. Targeted strategies for the validated biomarkers were searched and summarized. A total of 27 reported CSC biomarkers for HNSCC were identified and comprehensively evaluated. In regards to the expression pattern of CD44 in HNSCC, the expression patterns for the remaining 26 biomarkers presented 3 different tendencies. We managed to include all the 27 CSC biomarkers for HNSCC into 3 groups. Moreover, the biomarkers in each group indicated distinct clinicopathological features and a different overall survival status for HNSCC patients. The above information suggested the existence of CSC subpopulations in HNSCC. Accordingly, we demonstrated that precisely targeted strategies based on the CSC subgrouping clusters might effectively supplement conventional therapies, and benefit HNSCC patients. Further relevant studies are still necessary to improve treatment strategies for HNSCC based on the CSC area.
\end{abstract}

\section{Introduction}

Head and neck squamous cell carcinoma (HNSCC) refers to a group of biologically similar cancers arising from the mucous

Correspondence to: Dr Yan'an Wang or Dr Xi Yang, Department of Oral and Maxillofacial-Head and Neck Oncology, Shanghai Ninth People's Hospital, Shanghai Jiao Tong University, School of Medicine, 639 Zhizaoju Road, Shanghai 200011, P.R. China E-mail: wangya1982@sh9hospital.org; shore70001@126.com E-mail: yangxi16@163.com

${ }^{*}$ Contributed equally

Key words: bioinformatics, cancer stem cell, head and neck squamous cell carcinoma, biomarkers squamous epithelia in the head and neck area. HNSCC is an aggressive cancer with poor overall survival (1-4). In spite of the recent advancements in treatment modalities for HNSCC, the long-term survival rates have not significantly improved over the past decade (5). Currently, emerging evidence suggests that cancer stem cells (CSCs) are responsible for local recurrence, metastatic spread, and treatment resistance in HNSCC (6).

To date, research on CSCs has become profound, and CSCs have been functionally defined as a subset of tumor cells that exhibit the ability of self-renewal and multipotency in cancerous malignancy (7). CSCs only account for a minor proportion of the total cancerous burden but can play paramount roles in determining the outcomes of cancers (8). Thus, identification of CSCs provides novel therapeutic promise for improving cancer treatment $(9,10)$. Previous studies conducted in several types of cancer have reported that these CSCs exhibit increased expression of certain biomarkers resulting in the acquisition of stem-like properties $(11,12)$. Confirmation of these CSCs requires the identification of such molecular biomarkers (9).

Discovering effective biomarkers is critical to a better understanding of the biological features of CSCs. To date, several putative protein molecules have been proposed to identify the CSCs in HNSCC, including CD44, CD133, Nanog, Oct4, Sox 2 and ALDH1 (12-15). However, validity of these CSC biomarkers has been questioned recently, and the clinical significance of these molecules in HNSCC remains to be ascertained, especially based on large cohort data. The Cancer Genome Atlas (TCGA) project holds great promise for a comprehensive understanding of human cancer with powerful and detailed data $(16,17)$. The UCSC Cancer Genomics Browser presents the TCGA data in a coherent, integrated system with genomic, clinical annotation data in multiple views (18). In this study, we managed to collect the reported CSC biomarkers of HNSCC and analyze these biomarkers via bioinformatics based on the TCGA primary HNSCC cohort. We systematically demonstrated the expression patterns, clinical significance, and potential targeted strategies for these molecules in HNSCC.

\section{Materials and methods}

Searching for the reported CSC biomarkers for HNSCC. Studies were scanned by searching the electronic database 
PubMed with the terms 'cancer stem-like cells', 'cancer stem cells', 'tumor stem-like cells', 'tumor stem cells', 'CSCs', and 'head and neck squamous cell carcinoma', 'HNSCC'. In order to be included for further summary, the following criteria were met: i) an original research paper in a peer-reviewed journal; ii) studies in humans; iii) studies with validated evidence to demonstrate the reported biomarkers tightly concerned with the CSC characteristics of HNSCC. Conference abstracts, reviews, comments, case reports, and letters to the editor were excluded. Subsequently, all potentially eligible studies were retrieved and the following information was extracted: i) name of the reported CSC biomarker; ii) the reported clinical significance for each CSC biomarker in HNSCC areas. In addition, the encoding genes for the reported CSC biomarkers were annotated. We demonstrated the cellular location and biological roles for each reported CSC-related molecule based on The Human Protein Atlas. Search results for the CSC biomarkers of HNSCC are listed in Table I.

Bioinformatic analysis for the reported CSC biomarkers of HNSCC based on the TCGA primary HNSCC cohort. Bioinformatic analyses were performed based on the TCGA primary HNSCC cohort using the UCSC Xena Browser. Totally, 604 cases were searched, and only cases of primary HNSCC were filtered and included for further analysis for the gene expression patterns of each reported CSC biomarker. Expression heat-maps and Kaplan-Meier curves stratified by the defined gene were generated and clustered online, and detailed data were downloaded for subsequent statistical analysis. To illustrate the clinicopathological features of the reported CSC biomarkers, we downloaded and analyzed the detailed data for the expression level, pathological nodal extracapsular spread, lymphovascular invasion, neoplasm histologic grade, tumor size, nodal status, and pathologic stage.

Searching for targeted treatment based on the reported CSC biomarkers in cancer areas. Studies were scanned by searching electronic database PubMed for the targeted treatment based on the reported CSC biomarkers in the pan-cancer areas. Articles were reviewed to figure out and summary the targeted strategies in cancer areas based on the reported CSC biomarkers of HNSCC.

Statistical analysis. Statistical analyses were conducted with SPSS 20.0 software (IBM Corp., Armonk, NY, USA). Based on the detailed data for each biomarker, all cases involved were divided equally into two groups, a high-expression group and low-expression group. To illustrate the underlying relationship among the reported CSC biomarkers, crosstab analyses were performed and Chi-squared tests were used to assess the statistical significance for correlations between the gene expression level of CD44 and the gene expression levels of other biomarkers. In addition, Chi-squared tests were used to assess the statistical significance for correlations between the gene expression level of each biomarker and each clinicopathological variable. Xena Browser compares the different Kaplan-Meier curves using the log-rank test. $\mathrm{p}<0.05$ was considered to indicate a statistically significant difference. Venn diagrams were generated for clustering analyses.

\section{Results}

Detailed information for the reported CSC biomarkers of HNSCC. A total of 27 molecules, encoded by 28 genes, were demonstrated and reported to be tightly linked with the CSC properties of HNSCC. Detailed information for each reported biomarker has been summarized. As shown in Fig. 1A, cellular locations for these molecules are designated. Four molecules are located at the plasma membrane (CD44, EpCAM, CD10 and TAZ), 4 molecules in the cytoplasm (CD24, MT1-MMP, ALDH1 and GRP78), and 12 molecules in the nucleus (topoisomerase I/II $\alpha / \mathrm{III} \alpha$, Notch1, Brachyury, ABCG5, Sox2, SLC2A13, Nanog, KLF4, JMJD6 and EHMT2). In addition, there are 3 molecules distributed at both the plasma membrane and cytoplasm (c-Met, CD133, and CD166), 2 molecules at both the cytoplasm and nucleus (Oct4 and Bmi-1), and 1 molecule at both the plasma membrane and nucleus (ABCG2). Additionally, CD98 is widely scattered among the plasma membrane, cytoplasma, and nucleus.

Furthermore, we also characterized the biological roles for these molecules into 6 categories (Fig. 1B): replication regulation (topoisomerase I, II $\alpha$ and III $\alpha$ ), transcription regulation (TAZ, Oct4, Bmi-1, KLF4, Sox2, Nanog, EHMT2 and Brachyury), signal transducer (CD24, EpCAM, c-Met, CD133, CD44, CD166, CD98 and Notch1), transporter protein (SLC2A13, ABCG2 and ABCG5), enzyme (MT1-MMP, ALDH1, CD10 and JMJD6) and chaperone protein (GRP78). Accordingly, we observed some heterogeneity existing among these biomarkers more or less, indicating that there might be variable mechanisms in regulating the CSC behaviors of HNSCC for these molecules.

Underlying relationship among the reported CSC biomarkers based on the TCGA primary HNSCC cohort. Although these biomarkers have been reported to regulate the stem-like ability of HNSCC cells, evidence for the underlying relationship among these molecules has not been demonstrated previously. Herein, we aimed to choose the TCGA primary HNSCC cohort to comprehensively evaluate the underlying relationship and validate the clinical significance for each biomarker. To date, CD44 has reported to be the most frequently used biomarker for identifying the CSCs in $\operatorname{HNSCC}(19,20)$. In this study, we chose CD44 as a reference biomarker for the reported CSC biomarkers in HNSCC to analyze the clinical significance and underlying relationship among them. In total, there are 604 cases of HNSCC in the TCGA cohort, and only 528 cases of primary HNSCC were filtered and included for further analysis. By using the UCSC Xena browser, we generated a series of heatmaps referencing to the expression pattern of CD44 among the 520 cases (Fig. 2).

By data mining, we explored the expression patterns among these reported CSC biomarkers of HNSCC. We found that by referring to the expression pattern of CD44, the expression patterns of the remaining 26 biomarkers were clustered into three subgroups (Fig. 2). In the subgroup with a significantly positive correlation to the expression pattern of CD44 (Group A), the following biomarkers were included: CD98, c-Met, MT1-MMP, GRP78 and topoisomerase I. In the subgroup with a significantly negative correlation to the expression pattern of CD44 (Group B), the following 
Table I. Search results for the reported CSC biomarkers of HNSCC.

\begin{tabular}{|c|c|c|c|c|}
\hline CSC biomarker & Encoded gene & Cellular location & Biological roles & Clinical significance \\
\hline CD44 & $C D 44$ & Plasma membrane & Signal transducer & $\begin{array}{l}\text { Lymph node metastasis, } \\
\text { recurrence }\end{array}$ \\
\hline CD24 & $C D 24$ & Cellular vesicles & Signal transducer & $\begin{array}{l}\text { Tumorigenicity, } \\
\text { angiogenesis }\end{array}$ \\
\hline CD98 & $\begin{array}{l}S L C 7 A 5 \\
S L C 3 A 2\end{array}$ & $\begin{array}{l}\text { Nucleus, plasma membrane, } \\
\text { cytosol }\end{array}$ & $\begin{array}{l}\text { Signal transducer; } \\
\text { Amino acid transport }\end{array}$ & $\begin{array}{l}\text { Tumorigenicity, } \\
\text { recurrence }\end{array}$ \\
\hline EpCAM & EPCAM & Plasma membrane & Signal transducer & Chemoresistance \\
\hline c-Met & $M E T$ & $\begin{array}{l}\text { Plasma membrane, } \\
\text { cytosol }\end{array}$ & Signal transducer & $\begin{array}{l}\text { Chemoresistance, } \\
\text { metastasis }\end{array}$ \\
\hline CD133 & PROMI & $\begin{array}{l}\text { Plasma membrane, } \\
\text { cytoplasm }\end{array}$ & Signal transducer & $\begin{array}{l}\text { Metastasis, tumorigenicity, } \\
\text { chemoresistance }\end{array}$ \\
\hline CD166 & $A L C A M$ & $\begin{array}{l}\text { Plasma membrane, } \\
\text { cytoplasm }\end{array}$ & Signal transducer & Recurrence \\
\hline Notch1 & NOTCH1 & Nucleoplasm & Signal transducer & $\begin{array}{l}\text { Tumorigenicity, } \\
\text { chemoresistance }\end{array}$ \\
\hline CD10 & $M M E$ & Plasma membrane & $\begin{array}{l}\text { Zinc-dependent } \\
\text { metalloendoprotease }\end{array}$ & $\begin{array}{l}\text { Tumorigenicity, } \\
\text { chemoresistance }\end{array}$ \\
\hline MT1-MMP & $M M P 14$ & Cytoplasm & $\begin{array}{l}\text { Zinc-dependent } \\
\text { metalloendoprotease }\end{array}$ & $\begin{array}{l}\text { Recurrence, chemoresistance, } \\
\text { metastasis }\end{array}$ \\
\hline ALDH1 & $A L D H I A l$ & Cytosol & Detoxifying enzyme & $\begin{array}{l}\text { Recurrence, } \\
\text { radiochemoresistance }\end{array}$ \\
\hline $\mathrm{SOX} 2$ & $S O X 2$ & Nucleoplasm & Transcription factor & $\begin{array}{l}\text { Lymph node metastasis, } \\
\text { recurrence, chemoresistance }\end{array}$ \\
\hline Oct4 & POU5F1 & $\begin{array}{l}\text { Nucleoplasm, } \\
\text { cytosol }\end{array}$ & Transcription factor & $\begin{array}{l}\text { Lymph node metastasis, } \\
\text { chemoresistance }\end{array}$ \\
\hline Nanog & $N A N O G$ & Nucleoplasm & Transcription factor & $\begin{array}{l}\text { Chemoresistance, recurrence, } \\
\text { lymph node metastasis }\end{array}$ \\
\hline KLF4 & $K L F 4$ & Nucleoplasm & Transcription factor & $\begin{array}{l}\text { Lymph node metastasis, } \\
\text { distant metastasis }\end{array}$ \\
\hline Brachyury & $T$ & Nucleoplasm & Transcription factor & $\begin{array}{l}\text { Lymph node metastasis, } \\
\text { distant metastasis }\end{array}$ \\
\hline Bmi-1 & BMII & $\begin{array}{l}\text { Nucleus, nuclear bodies, } \\
\text { cytosol }\end{array}$ & $\begin{array}{l}\text { Transcriptional } \\
\text { repressors }\end{array}$ & $\begin{array}{l}\text { Chemoresistance, } \\
\text { metastasis }\end{array}$ \\
\hline $\begin{array}{l}\text { Topoisomerase I, } \\
\text { II } \alpha, \text { III } \alpha\end{array}$ & $\begin{array}{l}\text { TOP1, TOP } 2 A, \\
\text { TOP } 3 A\end{array}$ & Nucleus & Topoisomerase & $\begin{array}{l}\text { Lymph node } \\
\text { metastasis }\end{array}$ \\
\hline TAZ & $T A Z$ & Plasma membrane & $\begin{array}{l}\text { Transcriptional } \\
\text { regulation }\end{array}$ & $\begin{array}{l}\text { Tumor growth, } \\
\text { lymph node metastasis }\end{array}$ \\
\hline EHMT2 & EHMT2 & Nucleoplasm & $\begin{array}{l}\text { Euchromatic } \\
\text { methyltransferase }\end{array}$ & Lymph node metastasis \\
\hline JMJD6 & JMJD6 & Nucleoplasm & $\begin{array}{l}\text { Arginine demethylase, } \\
\text { lysine hydroxylase }\end{array}$ & $\begin{array}{l}\text { Recurrence, } \\
\text { chemoresistance }\end{array}$ \\
\hline ABCG2 & $A B C G 2$ & $\begin{array}{l}\text { Plasma membrane, } \\
\text { nucleus }\end{array}$ & $\begin{array}{l}\text { ABC transporter } \\
\text { protein }\end{array}$ & $\begin{array}{l}\text { Lymph node metastasis, } \\
\text { recurrence, chemoresistance }\end{array}$ \\
\hline ABCG5 & $A B C G 5$ & Nucleus & $\mathrm{ABC}$ transporter protein & Chemoresistance \\
\hline SLC2A13 & $S L C 2 A 13$ & Nuclear membrane & $\mathrm{H}^{+}$-myo-inositol transporter & Tumorigenicity \\
\hline GRP78 & HSPA5 & Cytosol & $\begin{array}{l}\text { Endoplasmic reticulum } \\
\text { chaperone }\end{array}$ & $\begin{array}{l}\text { Recurrence, radioresistance, } \\
\text { tumorigenicity }\end{array}$ \\
\hline
\end{tabular}

CSC, cancer stem cell; HNSCC, head and neck squamous cell carcinoma.

molecules were included: CD133, JMJD6, topoisomerase II $\alpha$, Notch1, Nanog, Oct4, EpCAM, ALDH1, Sox2, TAZ and
EHMT2. Moreover, the expression pattern of the following molecules were observed without significant correlation to 
A

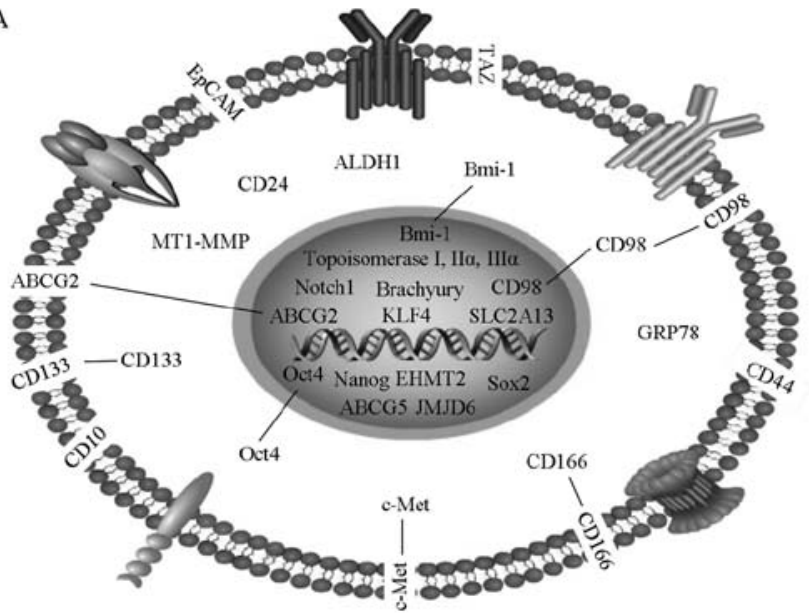

B

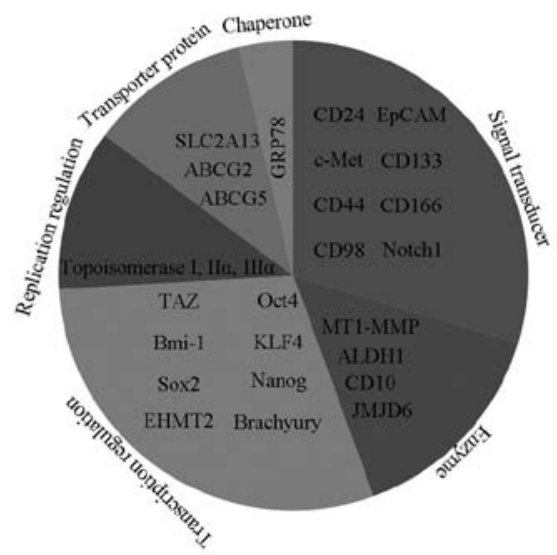

Figure 1. Schematic diagrams indicating the relationship among the reported CSC biomarkers for HNSCC based on (A) cellular location and (B) biological roles. CSC, cancer stem cell; HNSCC, head and neck squamous cell carcinoma.

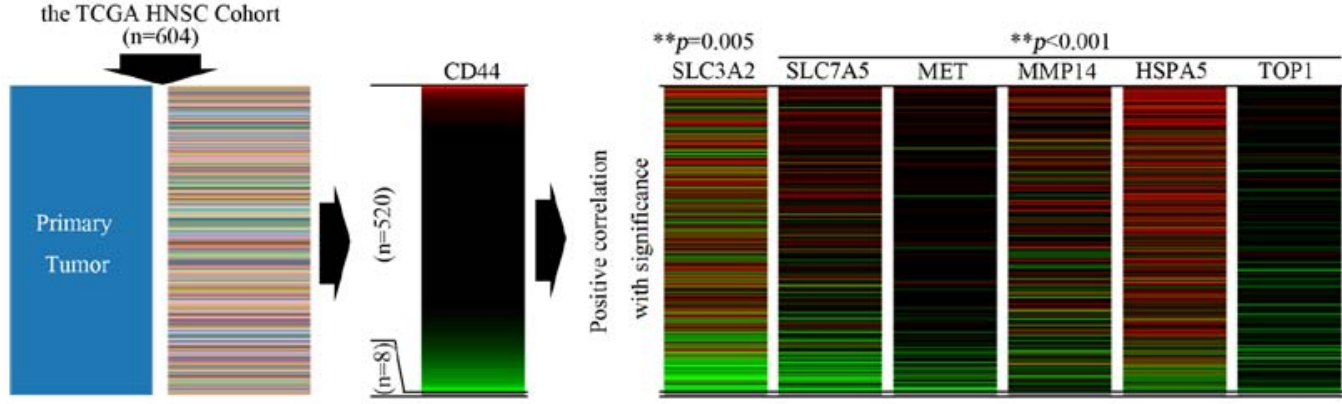

$(\mathrm{n}=528)$

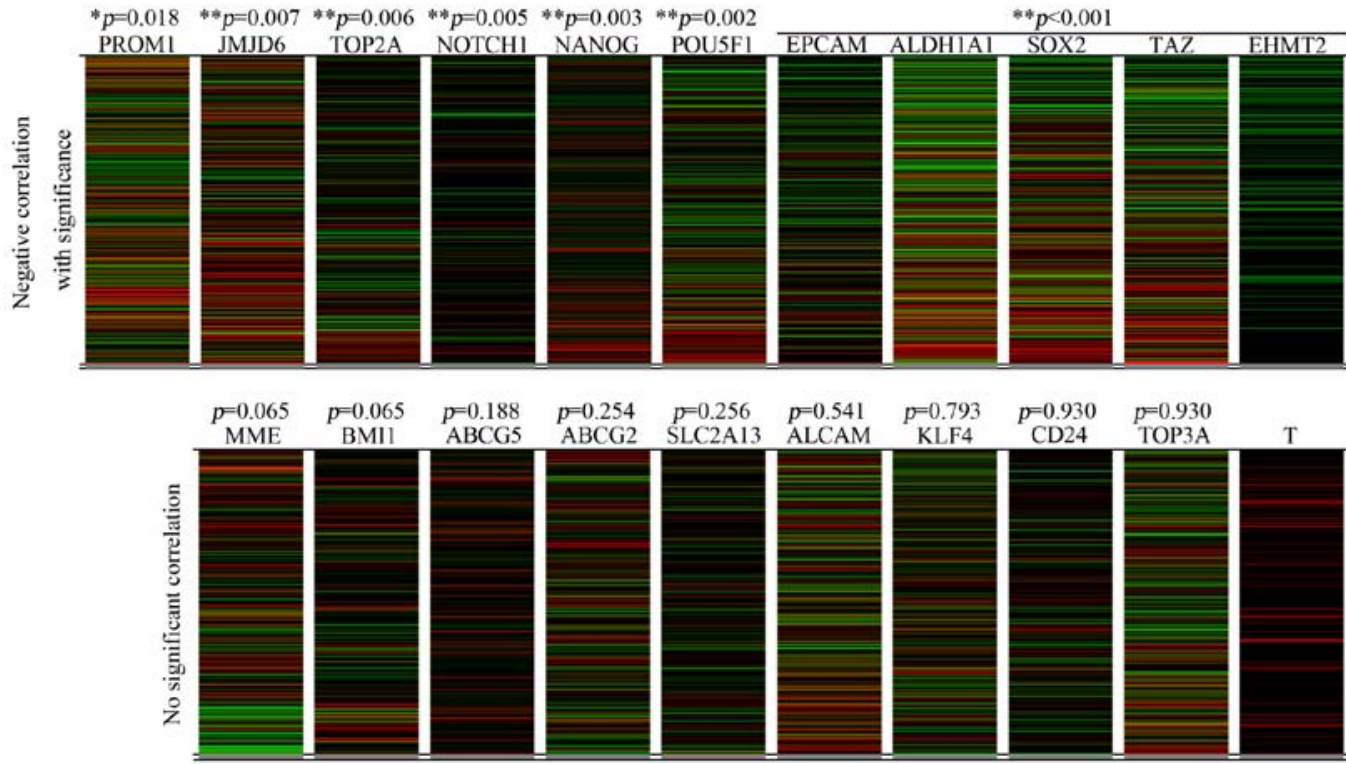

Figure 2. Heat maps from the UCSC Xena Browser based on the TCGA primary HNSCC cohort depicts the gene expression relationship between the CD44 and other reported CSC biomarkers. ( $\left.\mathrm{p}<0.05,{ }^{* *} \mathrm{p}<0.01\right)$. Among them, incomplete information for $\mathrm{T}$ was obtained for further statistical analysis. Colors illustrate the fold change (red, upregulation; green, downregulation). CSC, cancer stem cell; HNSCC, head and neck squamous cell carcinoma.

that of CD44 (Group C): CD10, Bmi-1, ABCG5, ABCG2, SLC2A13, CD166, KLF4, CD24 and topoisomerase III $\alpha$. Among these, the detailed data downloaded for Brachyury (encoded by T) was not enough for further studies. Thus, the incomplete heat-map for $\mathrm{T}$ was added at the end of Fig. 2 and no further analysis was performed for this biomarker. The above data indicated that great heterogeneity existed among the expression pattern of the reported CSC biomarkers in HNSCC, suggesting that subgrouping clusters might exist for all the CSCs in HNSCC. 
Table II. Clinicopathological evaluation for the reported CSC biomarkers based on the TCGA primary HNSCC cohort.

\begin{tabular}{|c|c|c|c|c|c|c|}
\hline & $\begin{array}{l}\text { Pathological nodal } \\
\text { extracapsular spread }\end{array}$ & $\begin{array}{l}\text { Lymphovascular } \\
\text { invasion }\end{array}$ & $\begin{array}{c}\text { Neoplasm } \\
\text { histologic grade }\end{array}$ & Tumor size & Nodal status & $\begin{array}{l}\text { Pathologic } \\
\text { stage }\end{array}$ \\
\hline & Yes/No & Yes/No & $\mathrm{G} 1+\mathrm{G} 2 / \mathrm{G} 3+\mathrm{G} 4$ & $\mathrm{~T} 1+\mathrm{T} 2 / \mathrm{T} 3+\mathrm{T} 4$ & $\mathrm{~N} 0 / \mathrm{N}^{+}$ & $\mathrm{I}+\mathrm{II} / \mathrm{III}+\mathrm{IV}$ \\
\hline CD44 & 0.932 & 0.275 & 0.074 & 0.848 & 0.403 & $0.011^{\mathrm{b}}$ \\
\hline \multicolumn{7}{|c|}{ Subgroup with a significantly positive correlation to the expression pattern of CD44 (Group A) } \\
\hline SLC3A2 & $0.004^{\mathrm{a}}$ & 0.778 & $0.001^{\mathrm{b}}$ & $0.004^{\mathrm{a}}$ & 0.451 & 0.154 \\
\hline SLC7A5 & 0.674 & 0.613 & $0.001^{\mathrm{b}}$ & 0.733 & $0.045^{\mathrm{b}}$ & 0.857 \\
\hline MET & 0.243 & 0.908 & 0.972 & 0.525 & 0.833 & 0.180 \\
\hline MMP14 & 0.714 & 0.392 & 0.993 & 0.455 & 0.298 & 0.986 \\
\hline HSPA5 & $0.022^{\mathrm{a}}$ & 0.754 & 0.177 & 0.324 & 0.267 & 0.785 \\
\hline TOP1 & 0.994 & $0.007^{\mathrm{b}}$ & $0.014^{\mathrm{b}}$ & 0.164 & 0.235 & 0.244 \\
\hline \multicolumn{7}{|c|}{ Subgroup with a significantly negative correlation to the expression pattern of CD44 (Group B) } \\
\hline TOP2A & 0.097 & 0.317 & $0.000^{\mathrm{a}}$ & 0.839 & 0.068 & 0.915 \\
\hline NOTCH1 & 0.732 & 0.087 & 0.068 & 0.216 & 0.264 & 0.160 \\
\hline NANOG & 0.327 & $0.032^{\mathrm{a}}$ & $0.043^{\mathrm{a}}$ & 0.775 & 0.934 & 0.812 \\
\hline PROM1 & 0.901 & 0.121 & 0.393 & 0.807 & 0.818 & 0.523 \\
\hline JMJD6 & $0.016^{\mathrm{a}}$ & 0.053 & 0.549 & $0.005^{*}$ & $0.017^{\mathrm{a}}$ & $0.000^{\mathrm{a}}$ \\
\hline EPCAM & 0.375 & $0.000^{\mathrm{a}}$ & 0.077 & 0.338 & 0.118 & $0.025^{\mathrm{a}}$ \\
\hline ALDH1A1 & 0.369 & 0.179 & 0.085 & 1.000 & 0.198 & 0.429 \\
\hline SOX2 & 1.000 & 0.180 & 0.157 & 0.925 & 0.692 & 0.214 \\
\hline POU5F1 & 0.608 & 0.179 & 0.224 & 0.257 & 0.693 & 0.653 \\
\hline TAZ & 0.304 & 0.093 & 0.362 & 0.572 & 0.693 & 0.142 \\
\hline EHMT2 & 0.126 & 0.092 & $0.011^{\mathrm{a}}$ & 0.132 & $0.003^{\mathrm{a}}$ & 1.000 \\
\hline \multicolumn{7}{|c|}{ Subgroup without a significant correlation to the expression patter of CD44 (Group C) } \\
\hline MME & 0.522 & 0.145 & $0.015^{\mathrm{b}}$ & 0.220 & 0.489 & 0.736 \\
\hline BMI1 & 0.123 & 0.117 & $0.012^{\mathrm{a}}$ & 0.451 & 0.693 & 0.572 \\
\hline ABCG2 & 0.523 & 0.180 & 0.129 & 0.925 & 0.374 & 1.000 \\
\hline ABCG5 & $0.007^{\mathrm{a}}$ & $0.007^{\mathrm{a}}$ & 0.420 & 0.300 & 0.093 & 0.072 \\
\hline SLC2A13 & 0.608 & 0.823 & 1.000 & 0.637 & 0.767 & 0.822 \\
\hline CD24 & 0.248 & $0.014^{\mathrm{b}}$ & $0.001^{\mathrm{b}}$ & 0.132 & 0.094 & 0.115 \\
\hline KLF4 & 0.523 & 0.313 & $0.000^{\mathrm{b}}$ & 0.637 & 0.489 & 0.574 \\
\hline ALCAM & 0.441 & 0.315 & $0.020^{\mathrm{a}}$ & 0.707 & 0.553 & 0.142 \\
\hline TOP3A & $0.029^{*}$ & 0.092 & 0.362 & 0.851 & 0.093 & 0.258 \\
\hline
\end{tabular}

${ }^{a}$ Positive correlation with significance; ${ }^{b}$ negative correlation with significance. CSC, cancer stem cell; HNSCC, head and neck squamous cell carcinoma.

Clinicopathological features and overall survival evaluation for the reported CSC biomarkers based on the TCGA primary HNSCC cohort. Based on the reported studies, the included 27 molecules have been identified to regulate cancer-stem like behaviors of HNSCC. The above data showed powerful evidence to indicate that these molecules might exert their roles with variable mechanisms. However, the validity and clinical significance for these biomarkers need to be further ascertained. Herein, we managed to validate the clinical significance for each biomarker based on the TCGA primary HNSCC cohort (Table II, Fig. 3).

As summarized in Table II, the molecules represented significantly positive correlation to the clinicopathological features were filtered and analyzed based on the TCGA primary HNSCC cohort. For the evaluation of nodal extracapsular spread, the molecules CD98 and GRP78 (Group A), JMJD6 (Group B), ABCG5 and topoisomerase III $\alpha$ (Group C) were identified as significant. For the evaluation of lymphovascular invasion, the molecules Nanog and EpCAM (Group B), and ABCG5 (Group C) were identified as significant. For the evaluation of histologic grade, the molecules topoisomerase II $\alpha$, Nanog and EHMT2 (Group B), and BMI-1 and CD166 (Group C) were identified as significant. For the evaluation of tumor size, the molecules CD98 (Group A) and JMJD6 (Group B) were identified as significant. For the evaluation of nodal status, the molecules JMJD6 and EHMT2 (Group B) were identified as significant. For the evaluation of pathologic stage, the molecules JMJD6 and 

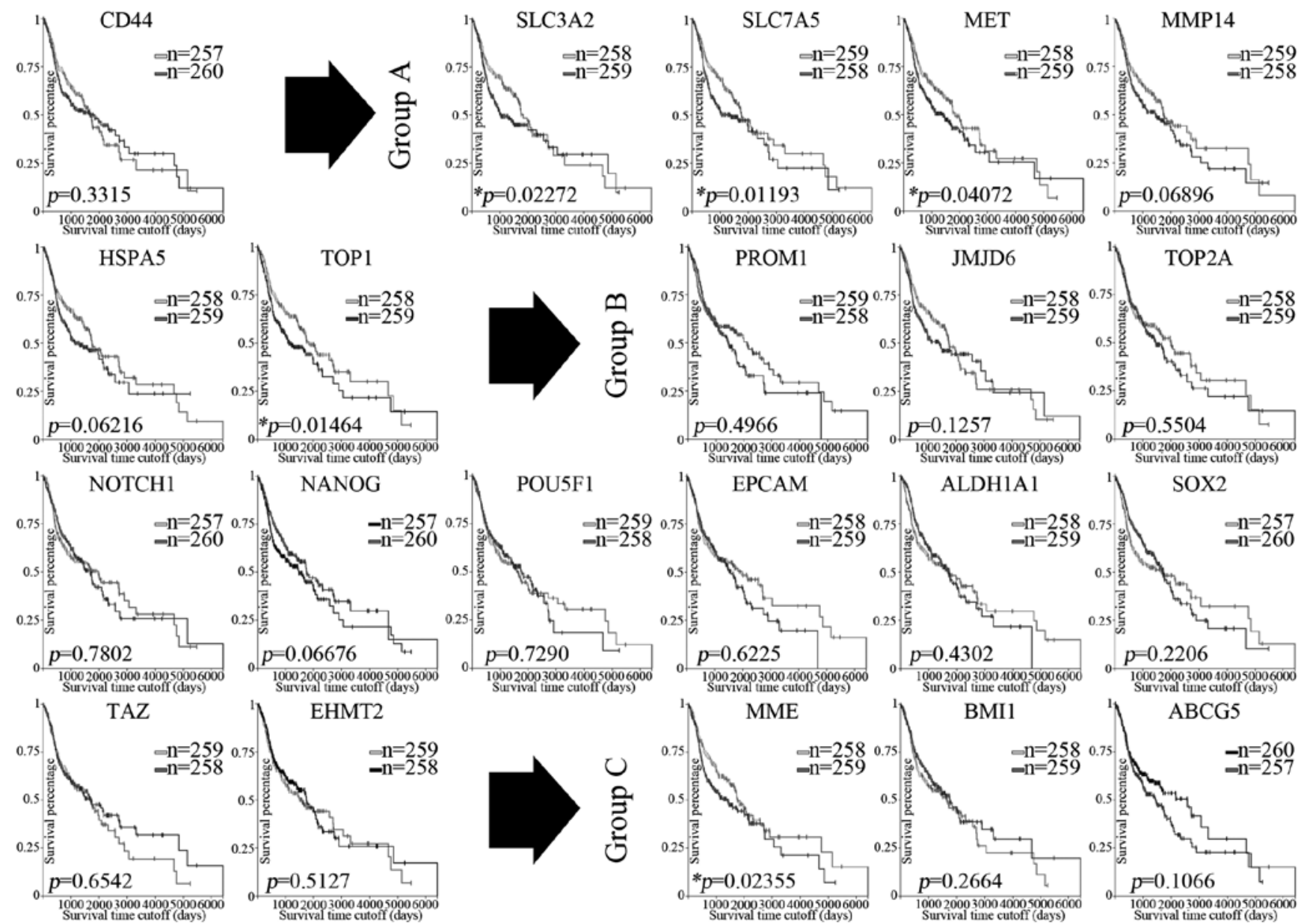

1 BMII
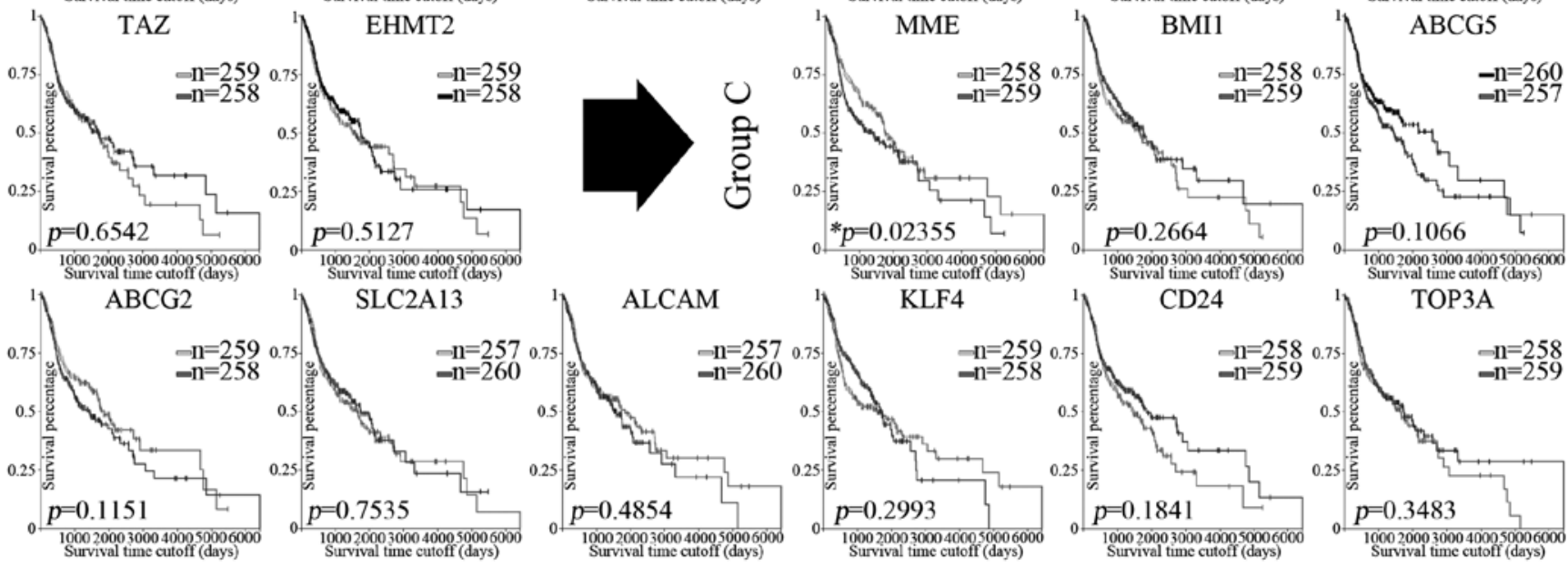

Figure 3. Kaplan-Meier analysis stratified by the gene expression for all the reported CSC biomarkers based on the TCGA primary HNSCC cohort from the UCSC Xena Browser ( $\left.{ }^{*} \mathrm{p}<0.05\right)$. Group A includes the reported CSC biomarkers in the subgroup with a significantly positive correlation to the expression pattern of CD44. Group B includes the reported CSC biomarkers in the subgroup with a significantly negative correlation to the expression pattern of CD44. Group C includes the reported CSC biomarkers in the subgroup without significant correlation to the expression pattern of CD44. CSC, cancer stem cell; HNSCC, head and neck squamous cell carcinoma.

EpCAM (Group B) were identified as significant. A series of Kaplan-Meier curves were generated to evaluate the prognostic significance for each reported CSC biomarker (Fig. 3). Accordingly, the higher expression of CD98, topoisomerase I, and c-Met (Group A), and CD10 (Group C) indicate significantly poorer overall survival (OS) for patients with HNSCC. Unexpectedly, we did not observe any significant correlations between the expression of biomarkers in Group B and the overall survival (OS) of the HNSCC patients.

By analyzing the clinical significance for each underlying subgroup, we proposed that biomarkers in Group A were mainly tightly related to clinical outcomes for HNSCC patients, and biomarkers in Group B were mainly tightly concerned with the malignant progression in HNSCC. The above data strongly indicate that the validated biomarkers might regulate
CSC properties and affect the clinicopathological features in HNSCC through different mechanisms, which warrant further attention to demonstrate the underlying heterogeneity.

Targeted treatment strategies for these CSC biomarkers in cancer areas. Currently, there are no targeted therapies for the CSCs in HNSCC. Despite the fact that HNSCC is a highly prevalent and deadly cancer, the survival rate for HNSCC patients has not shown any improvements for years. CSCs are responsible for relapse, chemoresistance and poor OS, and offer an attractive therapeutic target. Herein, we searched and summarized the reported targeted therapies for these molecules in pan-cancer areas (Table III). To date, various agents have been tested, including compounds, antibodies, and others. Moreover, some of these agents have 
Table III. Targeted therapies for the reported CSC markers of HNSCC in cancer areas.

\begin{tabular}{|c|c|c|c|}
\hline CSC molecule & Targeted compound & Targeted antibody & Others \\
\hline CD44 & Hyaluronic acid-based drug delivery & RG7356 & \\
\hline \multicolumn{4}{|c|}{ Subgroup with significantly positive correlation to the expression pattern of CD44 (Group A) } \\
\hline c-Met & $\begin{array}{l}\text { Cabozantinib, crizotinib, tepotinib, tivantinib, } \\
\text { other small-molecule inhibitors }\end{array}$ & BsAbs, mAb & \\
\hline Topoisomerase I & $\begin{array}{l}\text { Camptothecin, DXd, organic non-camptothecin } \\
\text { compounds, topotecan, LMP-400, NSC724998, } \\
\text { Iirinotecan, betulinic acid, SN-38 }\end{array}$ & & Metal complexes, OSI-211 \\
\hline GRP78 & Medicarpin, isoliquiritigenin, HA15 & & $\begin{array}{l}\text { Fusion protein, GMBP1, } \\
\text { KP1339/IT-139 }\end{array}$ \\
\hline MT1-MMP & & & Peptide-inhibitor \\
\hline \multicolumn{4}{|c|}{ Subgroup with significantly negative correlation to the expression pattern of CD44 (Group B) } \\
\hline Topoisomerase II $\alpha$ & $\begin{array}{l}\text { Pixantrone, glycyrrhetinic acid, halogenated } \\
\text { triterpenoid, } 2 \alpha \text {-bromo-dihydrobetulonic acid, CS1 }\end{array}$ & & D11 \\
\hline Notch1 & PF-03084014 & Brontictuzumab & \\
\hline EpCAM & EpCAM aptamer-mediated delivery & $\begin{array}{l}\text { mAbs, } \\
\text { catumaxomab }\end{array}$ & $\begin{array}{l}\text { Immunotoxin, adoptive T-cell } \\
\text { therapy, cytolytic fusion protein }\end{array}$ \\
\hline ALDH1 & Diethylaminobenzaldehyde & & \\
\hline Oct4 & Metformin & & \\
\hline CD133 & CD133 aptamer-mediated delivery & & Immunotoxin \\
\hline EHMT2 & UNC0638, BIX-01294 & & \\
\hline \multicolumn{4}{|c|}{ Subgroup without significant correlation to the expression patter of CD44 (Group C) } \\
\hline $\mathrm{CD} 24$ & Anti-CD24 based drug delivery & $\mathrm{mAb}$ & \\
\hline CD166, CD10 & & mAbs & \\
\hline Bmi-1 & PTC-209, РTC-028, РTC596 & & \\
\hline ABCG2 & $\begin{array}{l}\text { Anti-ABCG2 based drug delivery, Ko143, } \\
\text { PZ-39, MBL-II-141, YHO-13351, glafenine }\end{array}$ & Ko143 & \\
\hline
\end{tabular}

CSC, cancer stem cell; HNSCC, head and neck squamous cell carcinoma.

been well developed and used in other types of cancer clinically. No wonder, targeted therapies based on the validated CSC biomarkers would benefit more patients with HNSCC. Accordingly, we demonstrate that targeted therapies against c-Met, topoisomerase I, and GRP78 may improve the survival rate for HNSCC patients, and targeted therapies against topoisomerase II $\alpha$, EpCAM, and EHMT2 might greatly suppress the malignant progression of HNSCC.

\section{Discussion}

Emerging studies suggest that cancer stem cells are responsible for tumor initiation, cancer progression, metastasis and treatment resistance in HNSCC $(4,13)$. Several molecules have been identified to isolate and characterize CSCs in HNSCC, and almost all the CSC biomarkers established to date with a special emphasis on their impact on malignant progression and their potentially clinical significance in $\operatorname{HNSCC}(12,14,21)$. However, none of these biomarkers or their combinations have been well acknowledged or systematically validated. Consequently, there are no approved targeted strategies in regards to CSCs for the treatment of HNSCC patients (22).
Thus, there is a critical need for comprehensive evidence to evaluate the reported CSC biomarkers for HNSCC.

To date, a total of 27 molecules have been reported as potential CSC biomarkers for HNSCC. Nevertheless, the validity and underlying relationship among these molecules have not been demonstrated. Furthermore, several studies have reported the limitations and pitfalls underlying the isolation of CSCs with a single biomarker (23). Thus, we must analyze and discover the underlying heterogeneity among all the reported CSC biomarkers $(12,13,24-40)$. Primarily, we cannot deny the potential heterogeneity from the inconsistent experimental conditions, the power of experimental evidence, and the limited sample size for each study reporting the CSC biomarkers. What's more, it is of paramount importance to identify a reliable strategy to realize the essential heterogeneity derived from the CSCs of HNSCC. Recently, different CSC phenotypes have been implicated in breast cancer $(41,42)$. In HNSCC, it has been reported that Oct4, Sox 2 and CD133 are not consistently expressed in isolated CSCs (43). Herein, we proposed that the essential heterogeneity may result from the possible CSC subpopulations existing in HNSCC. Besides, understanding the underlying relationship among these 
CSC-related molecules is vitally important for demonstrating the biological roles for CSCs in HNSCC.

Recently, large-scale bioinformatic analyses based on the TCGA cohort have shown great priority for cancer research $(17,18)$, which could greatly avoid the potential heterogeneity from the experimental results and limited clinical sample sizes. In this study, we conducted a comprehensive analysis for the expression files of the reported CSC biomarkers in a large number of primary HNSCC patients from TCGA. By data mining, we managed to discover the relationship among these molecules and validate the significance for each molecule in clinicopathological features and OS for HNSCC. Consequently, the reported CSC biomarkers were clustered into 3 groups according to their expression pattern, indicating that there might be subgrouping clusters existing for all CSCs in HNSCC. Accordingly, we might propose 2 molecular signatures for the possible CSC clusters existing in HNSCC, 3 validated biomarkers in group A (CD98, GRP78 and topoisomerase I), and 5 validated biomarkers in group B (JMJD6, Nanog, EpCAM, topoisomerase II $\alpha$ and EHMT2).

Previous studies have reported that CSCs are responsible for cancer initiation and progression, and are especially resistant to conventional therapy $(1,12,30)$. In this study, filtered biomarkers belonging to group A were observed without significant correlation to the malignant progression of HNSCC, but significantly indicating worse OS for HNSCC patients. On the contrary, filtered biomarkers belonging to group B were shown to be significantly correlated to the malignant characteristics of HNSCC, but without significant correlation to the OS rates of HNSCC patients. As we know, the clinical outcomes for HNSCC are determined by malignant phenotypes and treatment responses of cancer cells. Thus, we may conclude that some CSCs are responsible for malignant phenotypes, but poorer responses to treatment strategies, and some CSCs may be responsible for worse malignant phenotypes, but better responses to treatment. Further studies for the underlying heterogeneity among all the CSCs in HNSCC are critically necessary in the future.

Treatment decisions for HNSCC are complex, and according to the US guidelines, a multidisciplinary approach is recommended (2). However, the prognosis of HNSCC remains very poor. Besides, there are still no approved targeted strategies for CSCs in HNSCC. Targeted strategies based on the validated CSC biomarkers may effectively supplement conventional therapies, and benefit HNSCC patients. In this study, we proposed that targeted strategies against c-Met, topoisomerase I, and GRP78 show great possible to improve the prognosis of HNSCC patients, and targeted strategies against topoisomerase II $\alpha$, EpCAM and EHMT2 may potentially suppress the malignant progression of HNSCC.

In conclusion, we comprehensively evaluated the 27 reported CSC biomarkers for HNSCC based on the TCGA primary HNSCC cohort. Accordingly, we managed to illustrate the underlying subgroup clusters among all the CSCs in HNSCC. We proposed that precisely targeted strategies based on the CSC subgroup clusters may well supplement conventional therapies, and benefit HNSCC patients. There is no doubt that numerous studies have improved and greatly furthered our understanding of the CSCs of HNSCC. However, more laboratory research and well-designed retrospective or prospective large-scale studies are still necessary to validate the conclusions derived from our study for eventually clinical translation.

\section{Acknowledgements}

Not applicable.

\section{Funding}

The present study was supported by the National Natural Science Foundation of China (nos. 81371164 and 81602367), the Science and Technology Commission of Shanghai Municipality (no. 15411950300).

\section{Availability of data and materials}

The datasets used during the present study are available from the corresponding author upon reasonable request.

\section{Authors' contributions}

XY and YW conceived and designed the experiments. MX and LL performed the experiments. MX, LL and SZ summarized and analyzed the data. MX, LL and XY contributed to writing and revising the manuscript. All authors read and approved the manuscript and agree to be accountable for all aspects of the research in ensuring that the accuracy or integrity of any part of the work are appropriately investigated and resolved.

\section{Ethics approval and consent to participate}

This study was approved by the Medical Ethics Committee of the Ninth People's Hospital, Shanghai Jiao Tong University School of Medicine.

\section{Patient consent for publication}

Not applicable.

\section{Competing interests}

The authors declare that they have no competing interests.

\section{References}

1. Sun S and Wang Z: Head neck squamous cell carcinoma c-Met ${ }^{+}$ cells display cancer stem cell properties and are responsible for cisplatin-resistance and metastasis. Int J Cancer 129: 2337-2348, 2011.

2. Pearson AT, Jackson TL and Nör JE: Modeling head and neck cancer stem cell-mediated tumorigenesis. Cell Mol Life Sci 73: 3279-3289, 2016

3. Leemans CR, Snijders PJF and Brakenhoff RH: The molecular landscape of head and neck cancer. Nat Rev Cancer 18: 269-282, 2018.

4. Yu CC, Lo WL, Chen YW, Huang PI, Hsu HS, Tseng LM, Hung SC, Kao SY, Chang CJ and Chiou SH: Bmi-1 regulates snail expression and promotes metastasis ability in head and neck squamous cancer-derived ALDH1 positive cells. J Oncol 2011: $1-16,2011$.

5. Ringash J: Survivorship and quality of life in head and neck cancer. J Clin Oncol 33: 3322-3327, 2015.

6. Prince ME and Ailles LE: Cancer stem cells in head and neck squamous cell cancer. J Clin Oncol 26: 2871-2875, 2008. 
7. Plaks V, Kong N and Werb Z: The cancer stem cell niche: How essential is the niche in regulating stemness of tumor cells? Cell Stem Cell 16: 225-238, 2015.

8. Sayed SI, Dwivedi RC, Katna R, Garg A, Pathak KA, Nutting CM, Rhys-Evans P, Harrington KJ and Kazi R: Implications of understanding cancer stem cell (CSC) biology in head and neck squamous cell cancer. Oral Oncol 47: 237-243, 2011.

9. Abbaszadegan MR, Bagheri V, Razavi MS, Momtazi AA, Sahebkar A and Gholamin M: Isolation, identification, and characterization of cancer stem cells (Review). J Cell Physiol 232. 2008-2018, 2017.

10. Wolmarans E, Boy SC, Nel S, Mercier AE and Pepper MS: Cancer stem cells in head and neck carcinomas: Identification and possible therapeutic implications. Adv Exp Med Biol: Nov 15, 2017 (Epub ahead of print).

11. Shaikh MV, Kala M and Nivsarkar M: CD90 a potential cancer stem cell marker and a therapeutic target. Cancer Biomark 16: 301-307, 2016.

12. Zhang Q, Shi S, Yen Y, Brown J, Ta JQ and Le AD: A subpopulation of $\mathrm{CD}_{133^{+}}$cancer stem-like cells characterized in human oral squamous cell carcinoma confer resistance to chemotherapy. Cancer Lett 289: 151-160, 2010.

13. Prince ME, Sivanandan R, Kaczorowski A, Wolf GT, Kaplan MJ, Dalerba P, Weissman IL, Clarke MF and Ailles LE: Identification of a subpopulation of cells with cancer stem cell properties in head and neck squamous cell carcinoma. Proc Natl Acad Sci USA 104: 973-978, 2007.

14. Zhou C and Sun B: The prognostic role of the cancer stem cell marker aldehyde dehydrogenase 1 in head and neck squamous cell carcinomas: A meta-analysis. Oral Oncol 50: 1144-1148, 2014.

15. Pozzi V,Sartini D, Rocchetti R, Santarelli A, Rubini C, Morganti S Giuliante R, Calabrese S, Di Ruscio G, Orlando F, et al: Identification and characterization of cancer stem cells from head and neck squamous cell carcinoma cell lines. Cell Physiol Biochem 36: 784-798, 2015.

16. Sun W, Bunn P, Jin C, Little P, Zhabotynsky V, Perou CM, Hayes DN, Chen M and Lin DY: The association between copy number aberration, DNA methylation and gene expression in tumor samples. Nucleic Acids Res 46: 3009-3018, 2018.

17. Marzouka NA, Eriksson P, Rovira C, Liedberg F, Sjödahl G and Höglund M: A validation and extended description of the Lund taxonomy for urothelial carcinoma using the TCGA cohort. Sci Rep 8: 3737, 2018.

18. Zhu J, Sanborn JZ, Benz S, Szeto C, Hsu F, Kuhn RM, Karolchik D, Archie J, Lenburg ME, Esserman LJ, et al: The UCSC cancer genomics browser. Nat Methods 6: 239-240, 2009.

19. Kokko LL, Hurme S, Maula SM, Alanen K, Grénman R, Kinnunen I and Ventelä S: Significance of site-specific prognosis of cancer stem cell marker CD44 in head and neck squamous-cell carcinoma. Oral Oncol 47: 510-516, 2011.

20. Judd NP, Winkler AE, Murillo-Sauca O, Brotman JJ, Law JH, Lewis JS Jr, Dunn GP, Bui JD, Sunwoo JB and Uppaluri R: ERK1/2 regulation of CD44 modulates oral cancer aggressiveness. Cancer Res 72: 365-374, 2012.

21. Major AG, Pitty LP and Farah CS: Cancer stem cell markers in head and neck squamous cell carcinoma. Stem Cells Int 2013: 319489, 2013

22. Kiang A, Yu MA and Ongkeko WM: Progress and pitfalls in the identification of cancer stem cell-targeting therapies in head and neck squamous cell carcinoma. Curr Med Chem 19: 6056-6064, 2012.

23. Gilormini M, Wozny AS, Battiston-Montagne P, Ardail D, Alphonse $\mathrm{G}$ and Rodriguez-Lafrasse C: Isolation and characterization of a head and neck squamous cell carcinoma subpopulation having stem cell characteristics. J Vis Exp 2016: e53958,2016.

24. Zimmerer RM, Ludwig N, Kampmann A, Bittermann G Spalthoff S, Jungheim M, Gellrich NC and Tavassol F: CD24 tumor-initiating cells from oral squamous cell carcinoma induce initial angiogenesis in vivo. Microvasc Res 112: 101-108, 2017.

25. Martens-de Kemp SR, Brink A, Stigter-Van Walsum M, Damen JM, Rustenburg F, Wu T, Van Wieringen WN, Schuurhuis GJ, Braakhuis BJ, Slijper M, et al: CD98 marks a subpopulation of head and neck squamous cell carcinoma cells with stem cell properties. Stem Cell Res 10: 477-488, 2013.
26. Waldron NN, Barsky SH, Dougherty PR and Vallera DA: A bispecific EpCAM/CD133-targeted toxin is effective against carcinoma. Target Oncol 9: 239-249, 2014.

27. Lim YC, Kang HJ and Moon JH: c-Met pathway promotes self-renewal and tumorigenecity of head and neck squamous cell carcinoma stem-like cell. Oral Oncol 50: 633-639, 2014.

28. Yan M, Yang X, Wang L, Clark D, Zuo H, Ye D, Chen W and Zhang P: Plasma membrane proteomics of tumor spheres identify CD166 as a novel marker for cancer stem-like cells in head and neck squamous cell carcinoma. Mol Cell Proteomics 12: 3271-3284, 2013

29. Lee SH, Do SI, Lee HJ, Kang HJ, Koo BS and Lim YC: Notch1 signaling contributes to stemness in head and neck squamous cell carcinoma. Lab Invest 96: 508-516, 2016.

30. Fukusumi T, Ishii H, Konno M, Yasui T, Nakahara S, Takenaka Y, Yamamoto Y, Nishikawa S, Kano Y, Ogawa H, et al: CD10 as a novel marker of therapeutic resistance and cancer stem cells in head and neck squamous cell carcinoma. Br J Cancer 111: 506-514, 2014

31. Yang CC, Zhu LF, Xu XH, Ning TY, Ye JH and Liu LK: Membrane Type 1 Matrix metalloproteinase induces an epithelial to mesenchymal transition and cancer stem cell-like properties in SCC9 cells. BMC Cancer 13: 171, 2013.

32. Chou MY, Hu FW, Yu CH and Yu CC: Sox 2 expression involvement in the oncogenicity and radiochemoresistance of oral cancer stem cells. Oral Oncol 51: 31-39, 2015.

33. Chiou SH, Yu CC, Huang CY, Lin SC, Liu CJ, Tsai TH, Chou SH, Chien CS, Ku HH and Lo JF: Positive correlations of Oct-4 and Nanog in oral cancer stem-like cells and high-grade oral squamous cell carcinoma. Clin Cancer Res 14: 4085-4095, 2008.

34. Chen D, Wu M, Li Y, Chang I, Yuan Q, Ekimyan-Salvo M, Deng P, Yu B, Yu Y, Dong J, et al: Targeting BMI1 ${ }^{+}$cancer stem cells overcomes chemoresistance and inhibits metastases in squamous cell carcinoma. Cell Stem Cell 20: 621-634.e6, 2017.

35. Oliveira-Costa JP, Oliveira LR, da Silveira GG, Soave DF, Soares FA and Ribeiro-Silva A: Topoisomerase expression in oral squamous cell carcinoma: Relationship with cancer stem cells profiles and lymph node metastasis. J Oral Pathol Med 41: 762-768, 2012.

36. Li Z, Wang Y, Zhu Y, Yuan C, Wang D, Zhang W, Qi B, Qiu J, Song X, Ye J, et al: The Hippo transducer TAZ promotes epithelial to mesenchymal transition and cancer stem cell maintenance in oral cancer. Mol Oncol 9: 1091-1105, 2015.

37. Lee CR, Lee SH, Rigas NK, Kim RH, Kang MK, Park NH and Shin KH: Elevated expression of JMJD6 is associated with oral carcinogenesis and maintains cancer stemness properties. Carcinogenesis 37: 119-128, 2016.

38. Shen B, Dong P, Li D and Gao S: Expression and function of ABCG2 in head and neck squamous cell carcinoma and cell lines. Exp Ther Med 2: 1151-1157, 2011.

39. Lee DG, Lee JH, Choi BK, Kim MJ, Kim SM, Kim KS Chang K, Park SH, Bae YS and Kwon BS: $\mathrm{H}^{+}$-myo-inositol transporter SLC2A13 as a potential marker for cancer stem cells in an oral squamous cell carcinoma. Curr Cancer Drug Targets 11: 966-975, 2011.

40. Wu MJ, Jan CI, Tsay YG, Yu YH, Huang CY, Lin SC, Liu CJ, Chen YS, Lo JF and Yu CC: Elimination of head and neck cancer initiating cells through targeting glucose regulated protein78 signaling. Mol Cancer 9: 283, 2010.

41. Da Cruz Paula A and Lopes C: Implications of different cancer stem cell phenotypes in breast cancer. Anticancer Res 37: 2173-2183, 2017.

42. Eun K, Ham SW and Kim H: Cancer stem cell heterogeneity: Origin and new perspectives on CSC targeting. BMB Rep 50: 117-125, 2017.

43. Han J, Fujisawa T, Husain SR and Puri RK: Identification and characterization of cancer stem cells in human head and neck squamous cell carcinoma. BMC Cancer 14: 173, 2014. 